\title{
Determinantes da duração esperada do emprego urbano e rural no Nordeste brasileiro
}

\author{
Paulo Aguiar do Monte ${ }^{1}$ \\ Mariângela Rangel Jacques Penido²
}

Resumo: Este trabalho tem como objetivo analisar os determinantes da duração no emprego nos estados do Nordeste para os anos 1993 e 2003. Para tanto, foram utilizados os microdados da Pesquisa Nacional por Amostra de Domicílios (PNAD), realizada pelo Instituto Brasileiro de Geografia e Estatística (IBGE). Os resultados obtidos por meio do modelo paramétrico evidenciam que a duração das relações de emprego é maior para os homens, chefes-de-família, brancos e trabalhadores com idade mais elevada. No que tange ao aspecto regional, verificou-se que os residentes nos estados de Pernambuco e Bahia - justamente os que possuem as maiores taxas de desemprego - apresentam maior rotatividade quando comparado aos demais estados nordestinos.

Palavras-chave: Duração; emprego urbano; emprego rural.

Abstract: This study seeks to examine the determinants of the duration in employment in all Northeastern states of Brazil for the years 1993 and 2003. In order to do so, we used the data from the National Survey per Residence Samples (PNAD) which is done by the Brazilian Institute of Geography and Statistics (IBGE), every year. Results obtained

${ }^{1}$ Professor Adjunto da Universidade Federal da Paraíba. Doutor em Economia pelo PIMES/UFPE, 2005. E-mail: pauloaguiardomonte@gmail.com ${ }^{2}$ Professora da Faculdade Arnaldo Janssen. Mestre em Economia pelo Cedeplar/ UFMG, 2002. E-mail: mariangelarjpenido@yahoo.com.br 
by the parametric model showed that the duration of the relationship of employment is higher for men and older workers. With regard to the regional aspect, it was found that residents in the states of Pernambuco and Bahia - precisely those with the highest unemployment rates - have higher turnover when compared to other northeastern states.

Key-words: Duration; urban employment; rural employment.

Classificação JEL: J23, J64.

\section{Introdução}

A permanência do trabalhador no emprego é um indicador importante para compreender o funcionamento do mercado de trabalho. Resumidamtente, é possível afirmar que quanto maior a permanência do indivíduo em uma determinada atividade, menor tende a ser o custo social provocado pela rotatividade do trabalho.

Neste artigo, a questão da dinâmica do emprego será analisada por meio da duração na ocupação que, por sua vez, está condicionada, principalmente, a fatores econômicos, pessoais e culturais, não atingindo, portanto, os indivíduos da mesma forma. Assim, este artigo tem dois objetivos: a) analisar descritivamente a dinâmica do emprego no setor rural e urbano; b) estimar em que medida determinadas características influenciam na permanência no emprego. Em ambos os casos, a partir de diferentes combinações de características observáveis dos indivíduos (gênero, grau de escolaridade, faixa etária, posição no domicílio) e da atividade econômica (setor de atividade, núcleo formal ou informal), tanto no meio urbano como no meio rural, procurar-se-á analisar a estrutura do emprego nas áreas citadas e suas respectivas associações com a duração no emprego, através de uma análise descritiva e de um estudo econométrico por meio do modelo de análise de sobrevivência. A análise estará restrita a região Nordeste, e terá como base as informações advindas da Pesquisa Nacional por Amostra de Domicílio (PNAD) dos anos de 1993 e 2003.

Além desta Introdução, o trabalho está organizado em mais cinco capítulos, desde uma breve revisão da literatura econômica, que 
investiga os fatores determinantes da permanência do trabalhador na ocupação (Capítulo 2), passando pelas considerações metodológicas e informações sobre a base de dados utilizada (Capítulo 3), finalizando com os resultados encontrados (Capítulos 4 e 5) e as considerações finais (Capítulo 6).

\section{A permanência no emprego: teoria e breve revisão da literatura}

A permanência no emprego pode ser vista como uma variável associada à qualidade dos postos de trabalho e à eficiência produtiva. O tempo de permanência do trabalhador em uma determinada ocupação é variável fundamental para medir a eficiência do mercado de trabalho em virtude dos custos gerados pelo aumento da rotatividade para os agentes econômicos (ofertante e demandante de mão-de-obra). Segundo Farber (1999), a explicação dessa associação é a existência de capital humano específico à atividade desenvolvida pelo trabalhador. Assim, um tempo pequeno de permanência na ocupação tende a acarretar prejuízos para a economia ao trazer perdas de produtividade para o demandante (empresas) e para o ofertante de mão-de-obra, podendo causar, no médio e longo prazos a redução do investimento em capital humano feito pelas firmas.

No que se refere à análise econométrica, a literatura sobre os estudos acerca da permanência no emprego já incorpora alguns estudos que recorrem à análise de duração. No entanto, a maior parte dos trabalhos desenvolvidos concentra-se na estimação da duração do desemprego (Chuang, 1999) (Bivar, 1993). Especificamente, em relação ao tempo de duração do emprego, ainda são escassos os artigos produzidos em nível internacional e, principalmente, nacional. No contexto internacional, podem-se destacar os trabalhos de Farber (1999), que enfoca a importância do capital humano adquirido para a permanência do trabalhador em uma ocupação, bem como, os custos gerados pela rotatividade do trabalho, e o de Halima (2005) que analisa a relação endógena no contrato de trabalho firmado entre empregado e empregador, indicando que a duração no emprego é maior quanto maior forem os salários recebidos pelo trabalhador.

No Brasil, podem-se identificar três linhas de pesquisa: a primeira 
é aquela que busca mensurar a rotatividade, dos quais se destacam os trabalhos de Corseuil, Ribeiro e Santos (2003) que, por meio dos dados da Relação Anual de Informações Sociais (Rais), calcularam as medidas de realocação do trabalhador e do emprego, e de Menezes Filho e Fernandes (2003) que, com os mesmos dados, estimaram os custos de mudança de trabalho no País. A segunda linha está relacionada à crença de que a alta rotatividade observada no mercado de trabalho brasileiro deve-se aos reduzidos custos de demissão no País, quando comparados a outros países da América Latina, bem como ao arranjo de alguns programas que criam incentivos perversos à rotatividade da mão-de-obra. Nessa linha, destacam-se os trabalhos de Barros, Corseuil e Foguel (2000), que enfocam as políticas passivas de proteção social, mostrando que sua aplicabilidade pode estar influindo na rotatividade da força de trabalho, com conseqüências negativas sobre a duração das relações de trabalho; e o de Gonzaga (2003) que analisa os efeitos de mudanças ocorridas na Constituição de 1988 e nas Leis do Trabalho em setembro de 2001. O autor verificou um aumento na duração média do emprego dos trabalhadores formais afetados pelas mudanças em relação àqueles que não foram afetados. A terceira e última linha de pesquisa se preocupa em investigar os determinantes da rotatividade do emprego, no qual se destacam dois trabalhos: o de Chahad, Orellano e Pichetti (2001), que estudam os determinantes da saída e das demissões por meio de um modelo probit bivariado, e o de Menezes, Pichetti e Fenandes (2002), que analisaram a duração nas relações de emprego em São Paulo durante o período de 1988 a 1999.

Similarmente ao estudo de Menezes, Pichetti e Fernandes (2002), este artigo procurará analisar a duração das relações de emprego. Será utilizada, contudo, outra base de dados (PNAD) e contemplará um número maior de estados - especificamente os da região Nordeste. Sendo assim, será possível fazer um estudo comparativo entre as áreas urbana e rural da região Nordeste e os macrosetores da economia, procurando abordar uma lacuna observada por Ramos e Carneiro (2002), em que a rotatividade parece estar influenciada pelo setor de atividade e a região geográfica. 


\section{Considerações metodológicas e base de dados}

\subsection{Considerações metodológicas}

Características inatas e da atividade desenvolvida pelo trabalhador certamente exercem importante papel na permanência do indivíduo no emprego. A questão empírica neste estudo é estimar em que medida certos atributos (sejam características pessoais ou relacionadas a aspectos econômicos) influenciam na permanência do indivíduo na ocupação. Para analisar a questão da duração das relações de emprego, utilizou-se a análise de sobrevivência. A vantagem desse tipo de análise é considerar as informações dos indivíduos cuja permanência na ocupação durou no mínimo o período observado na amostra, diferentemente de outros métodos estatísticos, que descartam tais informações e consideram apenas a duração completa.

Neste tipo de análise, a variável de interesse é o tempo até a ocorrência de determinado evento (falha) que, neste caso, consiste na saída do trabalhador da posição de ocupado. A partir dessa variável, duas outras informações se destacam: a função de risco e a função de sobrevivência.

Tanto a função risco como a função de sobrevivência podem ser estimadas por meio do método não-paramétrico ou dos modelos semiparamétricos e paramétricos. Segundo Colosimo (2001), as três categorias citadas apresentam, na seqüência descrita, um grau crescente de hipóteses de especificação e de poder de explicação - razão pela qual se optou pela terceira categoria neste estudo. Diversas distribuições de probabilidade podem ser assumidas para a variável tempo, dentre as quais se destaca a gamma generalizada e os seus casos especiais de distribuição (Weibull, exponencial e log-normal). ${ }^{3}$

Nos modelos de distribuição gamma generalizada, o logaritmo do tempo de sobrevivência é expresso como uma função linear das variáveis observadas, como segue:

$$
\log t=X^{\prime} \beta+\sigma v
$$

${ }_{3}^{3}$ Para um maior aprofundamento ver Colosimo (2001). 
A distribuição para v determinará qual dos casos especiais (exponencial, weibull e log-normal) será utilizado. Para a escolha da distribuição ideal, é realizado o teste da razão de verossimilhança. Considera-se como hipótese nula que o modelo de interesse é adequado, e como hipótese alternativa, que o modelo não é adequado. O teste é realizado a partir dos seguintes ajustes: 1) estima-se o modelo generalizado e obtém-se o valor do logarítimo da sua verossimilhança $\left[\log \mathrm{L}\left(\hat{\beta}_{G}\right)\right] ; 2$ ) estima-se o modelo de interesse e obtém-se o valor do logarítimo da sua verossimilhança $\left[\log \mathrm{L}\left(\hat{\beta}_{M}\right)\right]$.

A partir desses valores, calcula-se a estatística da razão de verossimilhança (3.2) que, sob $\mathrm{H}_{0}$, tem aproximadamente uma distribuição qui-quadrado com um grau de liberdade.

$$
\mathrm{TRV}=2 \log \mathrm{L}\left(\hat{\beta}_{G}\right)-2 \log \mathrm{L}\left(\hat{\beta}_{M}\right)
$$

Uma vez decidida a especificação, por meio do método de máxima verossimilhança, obtém-se as estimativas dos parâmetros do modelo e, através destas, será possível fazer inferências sobre a relação de cada variável com o tempo de permanência na ocupação.

\subsection{Base de dados}

A análise empírica feita aqui foi baseada nos microdados da PNAD para os anos de 1993 e 2003 . A escolha desses anos deve-se ao fato dos mesmos representarem dois momentos distintos da economia brasileira. O primeiro, um cenário inflacionário, ao passo que o segundo, um cenário de estabilidade de preços, permitindo, assim, uma análise temporal em um intervalo (10 anos) de significativas mudanças na economia do País.

Através das repostas à pergunta sobre o tempo de permanência no emprego atual, foi possível analisar a duração das relações de emprego e sua variação durante uma década. A escolha pelas informações da PNAD refere-se ao objetivo do estudo, cujas informações não se encontram nas demais pesquisas disponíveis de abrangência nacional, apesar de se reconhecer as limitações da mesma, uma vez que, por ser uma pesquisa anual, um único ponto no tempo é observado, não 
permitindo, assim, a observação exata do tempo de duração ${ }^{4}$. As informações referem-se aos estados da região Nordeste e foram limitadas aos indivíduos ocupados na semana de referência e situados na faixa etária entre 16 e 65 anos. Para um estudo diferencial, por área espacial, foram criados dois bancos de dados distintos, de acordo com a localidade de sua residência, se na área urbana ou na área rural.

As variáveis selecionadas para explicação do modelo foram assim construídas: Homem (variável que assume valor 1 se o indivíduo for do gênero masculino e 0, caso contrário), Idade (idade do trabalhador, medida em anos), Idade2 (idade do trabalhador ao quadrado), Escolaridade (Analfabeto - sem instrução ou menos de 1 ano de estudo -, $1^{\circ}$ Grau completo, $2^{\circ}$ Grau incompleto e $2^{\circ}$ Grau completo ou superior. Considera-se a categoria $1^{\circ}$ Grau incompleto como sendo a categoria referência), Chefe (assume valor 1 para chefe do domicílio e 0, caso contrário), Branca (assume valor 1 para raça/cor branca e 0, caso contrário). Formal ${ }^{5}$ (assume valor 1 para ocupados no setor formal e 0, caso contrário), Estado (variável categórica que divide a amostra segundo o estado, considerando-se Pernambuco como sendo a categoria referência).

É importante ressaltar que o modelo paramétrico será estimado por setor de atividade (Agrícola, Indústria, Comércio e Serviços) para 1993 e 2003, e que a variável dependente nesta análise é representada pelo tempo de permanência no emprego atual (em meses) que será explicada em função das variáveis descritas acima. Cabe salientar que um sinal positivo do coeficiente estimado de uma variável indica que a duração do emprego é maior, portanto, a rotatividade associada àquela variável é menor.

\footnotetext{
${ }^{4}$ Cabe ressaltar que, recentemente, a Pesquisa Mensal de Emprego (PME) incorporou na sua metodologia a questão do tempo de permanência no emprego atual. Essa pesquisa, entretanto, limita-se a seis regiões metropolitanas do Brasil, não contemplando informações sobre todos os estados nordestinos e nem sobre as áreas rural e urbana.

${ }^{5}$ Foram considerados inseridos no mercado formal os trabalhadores com registro de carteira assinada mais o servidor público, militar e empregador; enquanto que, no mercado informal, foram inseridos aqueles que conseguiram uma ocupação sem carteira assinada, mais os sem remuneração, trabalhadores na produção para o próprio consumo e ainda os por conta própria.
} 


\section{Evidências da população ocupada a partir da seleção da amostra}

Com base na amostra selecionada, o segmento dos indivíduos ocupados na semana de referência ficou representado por 85.012 (23.854 da área rural e 61.158 da área urbana), sendo 58,6\% homens e 41,4\% mulheres. Do total, cerca de $49 \%$ são chefes-de-família, segundo sua condição familiar. Na Tabela 1, abaixo, é possível observar que o percentual de trabalhadores urbanos é bastante superior ao de trabalhadores rurais em quase todos os estados ${ }^{6}$ e que houve aumento na concentração de trabalhadores nos centros urbanos entre 1993 e 2003, haja vista que a participação de trabalhadores urbanos saltou para $74,1 \%$.

Tabela 1. Percentual de trabalhadores ocupados, por área e estado (1993 e 2003)

\begin{tabular}{l|c|c|c|c}
\hline \multirow{2}{*}{ Estado } & \multicolumn{2}{c|}{1993} & \multicolumn{2}{c}{ 2003 } \\
\cline { 2 - 5 } & Urbano & Rural & Urbano & Rural \\
\hline Maranhão & 41,8 & 58,2 & 63,2 & 36,8 \\
\hline Piauí & 53,4 & 46,6 & 58,3 & 41,7 \\
\hline Ceará & 75,2 & 24,8 & 81,2 & 18,8 \\
\hline Rio Grande do Norte & 66,7 & 33,3 & 71,9 & 28,1 \\
\hline Paraíba & 63,1 & 36,9 & 73,6 & 26,4 \\
\hline Pernambuco & 81,5 & 18,5 & 79,7 & 20,3 \\
\hline Alagoas & 60,9 & 39,1 & 65,2 & 34,8 \\
\hline Sergipe & 65,8 & 34,2 & 77,0 & 23,0 \\
\hline Bahia & 67,2 & 32,8 & 72,2 & 27,8 \\
\hline & 68,7 & 31,9 & 74,1 & 26,0 \\
\hline
\end{tabular}

Fonte: Elaboração própria a partir dos dados da PNAD.

${ }^{6} \mathrm{O}$ êxodo rural tem se intensificado no Nordeste nas últimas décadas. Dentre os principais fatores destacam-se: a crise da pecuária provocada pelas estiagens, que se contrapuseram à expansão das áreas de pastagem, e a crise da economia açucareira, que reduziu as possibilidades de emprego no campo e tem influenciado para a retração dos sistemas de arrendamento e de parceria tradicionais no Nordeste do País. (Moreira, 2000). 
A Tabela 2 contém informações mais detalhadas a respeito da amostra selecionada, enfatizando a questão do gênero, idade, escolaridade e segmento de mercado. Para compreendê-la, deve-se observar que o percentual de trabalhadores ocupados está expresso em relação ao total de trabalhadores ocupados em uma determinada área (seja urbana ou rural). Em 1993, por exemplo, do total de trabalhadores ocupados na área urbana, cerca de $57,9 \%$ eram do gênero masculino, enquanto que, em 2003, este percentual reduziu para 56,7\%. Com respeito ao gênero do trabalhador, embora o número relativo de trabalhadores masculinos seja superior ao feminino, percebe-se que esta diferença é maior na área rural $^{7}$. Quanto à análise por faixa etária, destaca-se que, tanto em relação à área urbana como à rural, a participação dos ocupados nas faixas etárias mais baixas diminuiu, enquanto a participação nas faixas etárias mais elevadas aumenta no período 1993-2003. Em 1993, trabalhadores com idade entre 16 e 24 anos e 55 e 65 anos representavam, nesta ordem, $25,2 \%$ e 6,8\% na área urbana e 30,2\% e 10,8\% na área rural e, em 2003, as respectivas participações alteraram para $22,2 \%$ e 7,5\%; 27,6\% e $12 \%$, nas respectivas áreas. Em relação ao grau de escolaridade, percebe-se claramente a redução no percentual de ocupados das classes com menor grau de escolaridade e o aumento da participação das classes com maior grau de escolaridade, independente da área em questão; embora ainda seja evidente a maior escolaridade dos trabalhadores residentes nos centros urbanos em relação aos da zona rural.

As duas últimas variáveis de análise da Tabela 2 referem-se ao setor de atividade, no qual fica evidente a predominância do setor primário na zona rural, e ao segmento de mercado, no qual se observa a predominância do setor infomal, principalmente na área rural onde quase $90 \%$ das ocupações são informais ${ }^{8}$.

\footnotetext{
${ }^{7}$ Nestas áreas ainda são comuns a divisão do trabalho por gênero. Enquanto os homens exercem atividades de trabalho fora da residência, cabem às mulheres as atividades domésticas, ficando, dessa forma, o espaço público para o homem.

${ }^{8}$ Este elevado percentual decorre das atividades desenvolvidas no espaço rural do Nordeste brasileiro, onde se destacam as atividades agrícolas, preponderamente de carácter familiar ou subsistência.
} 
Tabela 2. Percentual de trabalhadores ocupados no Nordeste, por área (1993 e 2003)

\begin{tabular}{l|c|c|c|c}
\hline \multirow{2}{*}{ Variável } & \multicolumn{2}{|c|}{1993} & \multicolumn{2}{c}{2003} \\
\cline { 2 - 5 } & Urbano & Rural & Urbano & Rural \\
\hline
\end{tabular}

\begin{tabular}{l|l|l|l|l}
\hline Masculino & 57,9 & 60,1 & 56,7 & 62,2 \\
\hline Feminino & 42,0 & 39,8 & 43,3 & 37,8 \\
\hline
\end{tabular}

\section{Faixa Etária}

\begin{tabular}{l|c|c|c|c}
\hline De 16 a 24 anos & 25,2 & 30,2 & 22,2 & 27,6 \\
\hline De 25 a 34 anos & 30,6 & 23,8 & 29,4 & 24,7 \\
\hline De 35 a 44 anos & 23,6 & 19,8 & 25,1 & 20,0 \\
\hline De 45 a 54 anos & 13,6 & 15,1 & 15,9 & 15,8 \\
\hline De 55 a 65 anos & 6,8 & 10,8 & 7,5 & 12,0 \\
\hline
\end{tabular}

\section{Escolaridade}

\begin{tabular}{l|c|c|c|c}
\hline Sem instrução & 16,5 & 47,3 & 11,7 & 35,9 \\
\hline $1^{\circ}$ Grau incompleto & 44,3 & 46,6 & 37,3 & 52,0 \\
\hline $1^{\circ}$ Grau completo & 7,9 & 1,8 & 8,8 & 4,2 \\
\hline $2^{\circ}$ Grau incompleto & 21,6 & 3,4 & 31,4 & 7,3 \\
\hline $\begin{array}{l}2^{\circ} \text { Grau completo } \\
\text { ou superior }\end{array}$ & 9,5 & 0,7 & 10,8 & 0,7 \\
\hline
\end{tabular}

Setor de Atividade

\begin{tabular}{l|c|c|c|c}
\hline Agrícola & 9,1 & 72,7 & 10,0 & 78,5 \\
\hline Industrial & 20,5 & 10,4 & 19,3 & 7,2 \\
\hline Comércio & 18,5 & 3,5 & 23,2 & 3,8 \\
\hline Serviços & 52,0 & 13,4 & 47,5 & 10,5 \\
\hline \multicolumn{5}{|l}{ Segmento de mercado } \\
\hline \multicolumn{5}{l|}{ Informal } \\
\hline Formal & 57,5 & 88,7 & 59,8 & 89,2 \\
\hline
\end{tabular}

Fonte: Elaboração própria a partir dos dados da PNAD. 
A Tabela 3 apresenta o tempo médio de permanência na atividade, por ano e área geográfica. Os valores expressos, por área, revelam que o tempo de permanência (em meses) na ocupação rural é superior ao observado na ocupação urbana, indicando que a dinâmica do mercado urbano é superior à do mercado rural, ou seja, que a rotatividade na ocupação é menor nas áreas rurais. Uma possível explicação para este fenômeno pode ser atribuída a fatores de demanda (baixo dinamismo econômico) e de oferta de mão-de-obra (baixo nível de escolaridade dos trabalhadores) nas áreas rurais, que podem estar inibindo uma maior rotatividade na busca por melhores ocupações, no caso dos ofertantes, e por trabalhadores com maior produtividade, no caso dos demandantes.

Em relação ao gênero do trabalhador, não foram verificadas grandes diferenças no que diz respeito à rotatividade. Já no referente à faixa etária, fica evidente que com o aumento da idade, maior é a duração no emprego, seja qual for a área ou ano estudado. Por sua vez, a análise por grau de escolaridade mostra que, nos extremos das classes de escolaridade, maior é o tempo de permanência, ocorrendo o inverso nas faixas centrais. Por fim, em relação aos segmentos da economia, trabalhadores ocupados no segmento informal apresentaram uma menor rotatividade no emprego comparativamente aos do segmento formal - resultado, este, influenciado pelo maior período de permanência do emprego na área rural, dado que na área urbana o trabalhador ocupado no segmento formal possui um tempo de permanência maior. Entre os estados analisados, Maranhão e Piauí destacam-se, visto que apresentaram maior rotatividade. Já Pernambuco, Bahia e Rio Grande do Norte registraram menor transição. 
Tabela 3. Tempo de permanência, em meses, na atividade por ano e área geográfica (1993 e 2003)

\begin{tabular}{l|c|c|c|c|c|c}
\hline \multirow{2}{*}{ Variáveis } & \multicolumn{3}{c|}{1993} & \multicolumn{3}{c}{2003} \\
\cline { 2 - 7 } & Urbana & Rural & Total & Urbana & Rural & Total \\
\hline Gênero & 80,6 & 125,3 & 94,9 & 85,2 & 138,8 & 100,1 \\
\hline Masculino & 78,8 & 134,9 & 95,7 & 80,3 & 152,9 & 97,3 \\
\hline Feminino
\end{tabular}

Faixa Etária

\begin{tabular}{|c|c|c|c|c|c|c|}
\hline De 16 a 24 anos & 27,6 & 55,6 & 37,5 & 27,0 & 59,8 & 36,9 \\
\hline De 25 a 34 anos & 54,6 & 88,4 & 63,4 & 52,4 & 96,9 & 62,5 \\
\hline De 35 a 44 anos & 98,7 & 143,4 & 111,1 & 95,7 & 153,8 & 108,4 \\
\hline De 45 a 54 anos & 146,2 & 205,0 & 165,9 & 145,8 & 224,2 & 166,1 \\
\hline De 55 a 65 anos & 188,3 & 291,3 & 231,7 & 195,1 & 313,3 & 237,8 \\
\hline \multicolumn{7}{|l|}{ Grau de Escolaridade } \\
\hline Sem instrução & 100,9 & 156,6 & 132,3 & 125,7 & 196,6 & 162,4 \\
\hline $1^{\circ} \mathrm{Grau}$ incompleto & 73,4 & 107,3 & 84,4 & 80,2 & 122,9 & 94,2 \\
\hline $1^{\circ}$ Grau completo & 64,9 & 82,6 & 66,6 & 70,0 & 83,1 & 71,9 \\
\hline $2^{\circ} \mathrm{Grau}$ incompleto & 72,5 & 76,2 & 72,7 & 68,6 & 74,4 & 69,0 \\
\hline $\begin{array}{c}2^{\circ} \text { Grau completo } \\
\text { mais superior }\end{array}$ & 102,4 & 113,4 & 102,8 & 99,4 & 110,0 & 99,6 \\
\hline \multicolumn{7}{|l|}{ Segmento de Mercado } \\
\hline Formal & 85,8 & 100,6 & 87,4 & 87,9 & 97,9 & 88,7 \\
\hline Informal & 75,4 & 132,8 & 99,1 & 79,9 & 149,7 & 103,8 \\
\hline \multicolumn{7}{|l|}{ Estado } \\
\hline Maranhão & 88,5 & 136,9 & 116,7 & 98,3 & 191,5 & 132,6 \\
\hline Piauí & 91,6 & 176,4 & 131,1 & 89,2 & 143,6 & 111,9 \\
\hline Ceará & 80,6 & 131,2 & 93,2 & 85,9 & 156,8 & 99,3 \\
\hline Rio Grande do Norte & 88,8 & 105,9 & 94,5 & 78,0 & 102,4 & 84,9 \\
\hline Paraíba & 94,3 & 137,0 & 110,1 & 91,4 & 116,9 & 98,1 \\
\hline Pernambuco & 75,2 & 117,5 & 83,0 & 79,6 & 129,2 & 89,6 \\
\hline Alagoas & 82,1 & 114,0 & 94,6 & 83,0 & 155,1 & 108,1 \\
\hline Sergipe & 79,7 & 131,4 & 97,4 & 87,2 & 143,4 & 100,1 \\
\hline Bahia & 76,0 & 121,7 & 91,0 & 78,5 & 142,8 & 96,4 \\
\hline Total & 79,8 & 129,1 & 95,3 & 83,1 & 144,1 & 98,9 \\
\hline
\end{tabular}

Fonte: Elaboração própria a partir dos dados da PNAD. 
Na Tabela 4, que contém as informações sobre o tempo médio de permanência por setor de atividade econômica, se percebe que em todos os setores, com exceção do terciário (serviços), a permanência na ocupação é maior para os trabalhadores da área rural. Enquanto no setor primário, o trabalhador urbano permanece, em média, 144,4 meses numa mesma ocupação; no setor rural este tempo de permanência sobe para 162 meses, diferente do verificado no setor terciário (serviços), no qual o tempo cai de 79,1 para 73 .

Tabela 4. Tempo de permanência, em meses, na atividade por setor e área geográfica (2003)

\begin{tabular}{|c|c|c|c|c|c|c|c|c|}
\hline \multirow{2}{*}{ Variável } & \multicolumn{2}{|c|}{ Agrícola } & \multicolumn{2}{|c|}{ Indústria } & \multicolumn{2}{|c|}{ Comércio } & \multicolumn{2}{|c|}{ Serviços } \\
\hline & Urbana & Rural & Urbana & Rural & Urbana & Rural & Urbana & Rural \\
\hline \multicolumn{9}{|l|}{ Gênero } \\
\hline Masculino & 137,1 & 152,4 & 77,4 & 73,1 & 73,8 & 77,3 & 80,3 & 68,2 \\
\hline Feminino & 164,5 & 180,6 & 87,3 & 129,0 & 57,1 & 59,7 & 78,1 & 75,4 \\
\hline \multicolumn{9}{|l|}{ Faixa Etária } \\
\hline De 16 a 24 anos & 52,1 & 67,5 & 25,9 & 41,1 & 26,6 & 29,1 & 21,7 & 26,1 \\
\hline De 25 a 34 anos & 84,3 & 111,2 & 52,6 & 69,5 & 52,3 & 51,8 & 47,8 & 50,2 \\
\hline De 35 a 44 anos & 138,6 & 170,5 & 95,0 & 119,3 & 83,2 & 89,1 & 94,8 & 98,8 \\
\hline De 45 a 54 anos & 204,7 & 242,9 & 141,7 & 154,7 & 114,6 & 133,0 & 145,8 & 135,5 \\
\hline De 55 a 65 anos & 274,3 & 327,2 & 190,2 & 211,1 & 148,4 & 178,2 & 172,1 & 155,2 \\
\hline \multicolumn{9}{|l|}{ Escolaridade } \\
\hline Sem instrução & 185,4 & 207,3 & 110,5 & 119,4 & 97,1 & 100,7 & 87,3 & 87,3 \\
\hline $1^{\circ}$ Grau incompleto & 124,7 & 135,7 & 77,8 & 89,9 & 72,5 & 73,0 & 71,3 & 66,4 \\
\hline $1^{\circ}$ Grau completo & 97,3 & 98,9 & 74,1 & 63,0 & 63,7 & 45,1 & 68,7 & 65,6 \\
\hline $2^{\circ}$ Grau incompleto & 89,1 & 86,8 & 69,3 & 59,4 & 56,4 & 50,2 & 73,9 & 71,1 \\
\hline $\begin{array}{l}2^{\circ} \text { Grau completo } \\
\text { superior }\end{array}$ & 125,5 & 152,0 & 97,3 & 62,1 & 70,4 & 30,9 & 103,8 & 120,1 \\
\hline \multicolumn{9}{|l|}{ Segmento de Mercado } \\
\hline Formal & 96,4 & 100,9 & 67,4 & 66,3 & 60,1 & 47,3 & 103,5 & 115,7 \\
\hline Informal & 150,9 & 165,8 & 88,9 & 100,8 & 71,2 & 73,2 & 55,4 & 47,6 \\
\hline \multicolumn{9}{|l|}{ Estado } \\
\hline Maranhão & 223,8 & 216,8 & 82,1 & 76,5 & 57,4 & 77,2 & 77,5 & 76,1 \\
\hline Piauí & 136,2 & 156,2 & 74,3 & 80,2 & 67,3 & 56,9 & 83,3 & 69,8 \\
\hline Ceará & 199,6 & 178,6 & 76,6 & 114,1 & 69,4 & 92,9 & 78,3 & 76,8 \\
\hline Rio Grande do Norte & 112,1 & 126,9 & 77,9 & 62,7 & 58,9 & 57,4 & 81,3 & 68,2 \\
\hline
\end{tabular}


Tabela 4. Continuação

\begin{tabular}{l|c|c|c|c|c|c|c|c}
\hline Paraíba & 120,4 & 126,9 & 75,4 & 90,5 & 69,9 & 79,4 & 99,4 & 97,7 \\
\hline Pernambuco & 98,2 & 145,8 & 84,3 & 67,6 & 72,0 & 75,4 & 79,0 & 61,0 \\
\hline Alagoas & 108,5 & 167,9 & 77,7 & 114,9 & 62,8 & 67,0 & 85,5 & 106,8 \\
\hline Sergipe & 130,3 & 162,0 & 89,8 & 86,5 & 76,5 & 93,0 & 84,4 & 80,3 \\
\hline Bahia & 136,0 & 158,6 & 80,6 & 102,2 & 64,7 & 53,6 & 73,6 & 62,8 \\
\hline \multicolumn{1}{c}{ Total } & 144,4 & 162,0 & 80,0 & 91,9 & 67,5 & 69,9 & 79,1 & 73,0 \\
\hline
\end{tabular}

Fonte: Elaboração própria a partir dos dados da PNAD.

Embora o emprego rural venha sofrendo os impactos da substituição das lavouras intensivas em trabalho, da ocupação das fronteiras com base na pecuária e, particularmente, do progresso tecnológico, o trabalhador rural tem permanecido mais tempo na sua ocupação se comparado ao trabalhador urbano.

No setor agrícola, as atividades predominantes foram cultivo de milho, de mandioca, de hortaliças, legumes e outros produtos de horticultura. Essas atividades demandam trabalhadores menos qualificados, o que pode justificar a menor rotatividade nestas áreas. Verificou-se, ainda, a predominância de estabelecimentos com até dois funcionários permanentes. Já no setor industrial, o resultado encontrado deve ser visto com ressalva, haja vista seu baixo dinâmismo na área rural. Os dados evidenciam que as atividades que se sobressaem são fabricação de artefatos têxteis a partir de tecidos (exceto vestuário) e construção civil, ou seja, segmentos em que se exige baixa escolaridade dos trabalhadores ocupados, fator que influencia para a queda da rotatividade. Por sua vez, a menor duração observada no setor de serviços pode ser explicada, por um lado, pela necessidade de atualização do trabalhador, uma vez que se verifica a predominância das atividades de educação regular, supletiva e especial pública, e, por outro lado, pelo baixo nível de escolaridade exigido ao serviços domésticos, também predominantes neste setor. 


\section{Resultados e discussões}

Conforme mencionado na seção 3.1., os modelos paramétricos requerem a especificação de uma distribuição para a variável tempo. Sendo assim, decidiu-se realizar o teste de verossimilhança, a fim de selecionar a melhor especificação. A importância desse tipo de teste deve-se à necessidade de adoção de um modelo adequado aos dados, uma vez que, do contrário, toda a análise estatística fica comprometida e, conseqüentemente, as respostas às perguntas de interesse ficam distorcidas. Os resultados dos testes de verossimilhança estão descritos na Tabela 5. Nesta, é possível perceber que, para a área urbana, em 1993, a variável tempo referente ao comércio não segue uma distribuição gamma, o mesmo ocorrendo em 2003, para o comércio e a indústria. Já no espaço rural (2003), para os setores de comércio e serviços, não foram observadas distribuições gamma para a variável tempo - nos demais setores e anos, a distribuição gamma se mostrou a mais adequada para descrever a variável tempo. Para os casos em que tanto a distribuição Weibull quanto a Exponencial se mostrarm adequadas, optou-se pela última, já que se trata de um caso particular da primeira. 
Tabela 5. Teste de Verossimilhança por área, setor de atividade e ano (1993 e 2003)

\begin{tabular}{|c|c|c|c|c|}
\hline \multirow{2}{*}{ Distribuição } & \multicolumn{4}{|c|}{ ÁREA URBANA } \\
\hline & Agrícola & Indústria & Comércio & Serviços \\
\hline \multicolumn{5}{|l|}{1993} \\
\hline Gamma & $-7127,7$ & $-16842,8$ & $-1237,6$ & $-39497,8$ \\
\hline Exponencial & $-3704,5(281,3)$ & $-8494,3(145,8)$ & $-619,6(1,7)$ & $-19838,2(178,6)$ \\
\hline Weibull & $-3701,5(275,3)$ & $-8451,6(60,3)$ & $-619,5(1,4)$ & $-19811,2(124,6)$ \\
\hline Log-normal & $-3982,6(837,5)$ & $-8778,2(713,5)$ & $-647,0(56,3)$ & $-20794,1(2090,3)$ \\
\hline \multicolumn{5}{|l|}{2003} \\
\hline Gamma & $-21300,4$ & $-4193,4$ & $-14327,5$ & $-4728,4$ \\
\hline Exponencial & $-11816,4(2332,3)$ & $-2254,5(315,6)$ & $-7164,4(1,3)$ & $-2370,3(12,3)$ \\
\hline Weibull & $-11481,7(1662,9)$ & $-2140,6(87,7)$ & $-7163,9(0,3)$ & $-2370,1(11,8)$ \\
\hline Log-normal & $-13280,3(5260,1)$ & $-2096,7(0,1)$ & $-7428,7(530,0)$ & $-2460,6(192,8)$ \\
\hline \multirow{2}{*}{ Distribuição } & \multicolumn{4}{|c|}{ ÁREA RURAL } \\
\hline & Agrícola & Indústria & Comércio & Serviços \\
\hline \multicolumn{5}{|l|}{1993} \\
\hline Gamma & $-11527,1$ & $-22526,8$ & $-26326,5$ & $-54397,6$ \\
\hline Exponencial & $-6099,6(672,2)$ & $-11399,9(272,9)$ & $-13170,1(13,6)$ & $-27236,02(74,5)$ \\
\hline Weibull & $-6080,5(633,8)$ & $-11366,5(206,2)$ & $-13166,7(6,9)$ & $-27228,2(58,8)$ \\
\hline Log-normal & $-6549,3(151,74)$ & $-12010,6(1494,3)$ & $-13666,3(1000,6)$ & $-28437,9(2478,2)$ \\
\hline \multicolumn{5}{|l|}{2003} \\
\hline Gamma & $-25358,7$ & $-2932,1$ & $-1390,5$ & $-3957,9$ \\
\hline Exponencial & $-14118,8(2878,8)$ & $-1495,6(59,1)$ & $-699,7(9,0)$ & $-1986,1(14,3)$ \\
\hline Weibull & $-13779,3(2199,8)$ & $-1492,3(52,6)$ & $-697,0(3,5)$ & $-1979,1(0,4)$ \\
\hline Log-normal & $-15918,2(6477,7)$ & $-1583,9(235,8)$ & $-736,6(82,5)$ & $-2063,2(168,6)$ \\
\hline
\end{tabular}

Fonte: Elaboração própria a partir dos dados da PNAD.

Notas: O valor apresentado é o $2 \log L$ e a estatística teste está entre parênteses. Aquele em destaque significa que a distribuição é adequada. 
Uma vez decidida a distribuição a ser assumida para a variável tempo, é possível interpretar as estimativas obtidas. A Tabela 6 apresenta os resultados do modelo paramétrico para o setor agrícola. Os coeficientes estimados apresentaram sinais similares tanto para a amostra da área urbana quanto para a da área rural, indicando que os determinantes da permanência na atividade são os mesmos para os ocupados no setor primário da economia. No que concerne ao determinante faixa etária, os resultados mostraram que, quanto maior a idade, maior tende a ser a permanência no emprego, apesar de se verificar que a intensidade dos parâmetros diminui quando se analisa a variável idade elevada ao quadrado. Quanto ao nível de escolaridade, de uma forma geral, os indivíduos com menos de 1 ano de estudo (sem instrução) apresentam menor rotatividade quando comparados àqueles com nível de escolaridade superior. Este resultado encontra-se em consonância com a Tabela 4 , apresentada anteriormente, indicando que os indivíduos com baixa escolaridade tendem a permanecer mais tempo na atividade, possivelmente devido ao nível de qualificação (capital humano) que não lhe permite alcançar outras atividades que sejam mais bem remuneradas.

Em relação à condição na família, especificamente os chefes-defamília, os números mostram que os mesmos tendem a permanecer mais tempo no emprego, visto que estes são os maiores responsáveis pelo sustento da família. Ademais, os trabalhadores ocupados no segmento formal apresentaram maior rotatividade no emprego, fato que pode estar associado ao aumento do emprego informal no setor agrícola, haja vista que o coeficiente estimado foi superior na área rural em relação à área urbana. Quanto à raça, possivelmente outras variáveis devam estar interferindo no resultado (como a questão da escolaridade ou o fator discriminação) da permanência no emprego. Por fim, no que se refere ao aspecto regional, os trabalhadores ocupados no Maranhão, Piauí, Rio Grande do Norte e Paraíba tendem a apresentar menor rotatividade quando comparado aos ocupados de Pernambuco, ao passo que, em relação aos ocupados na Bahia, Alagoas e Sergipe verifica-se o inverso. 
Tabela 6. Resultados do modelo paramétrico no setor agrícola, por ano (1993 e 2003)

\begin{tabular}{|c|c|c|c|c|}
\hline \multirow{2}{*}{ Variável } & \multicolumn{2}{|c|}{ ÁREA URBANA } & \multicolumn{2}{|c|}{ ÁREA RURAL } \\
\hline & 1993 & 2003 & 1993 & 2003 \\
\hline Homem & $-0,027^{*}(0,033)$ & $-0,057^{*}(0,021)$ & $-0,0109 *(0,014)$ & $-0,029 *(0,012)$ \\
\hline Idade & $0,299 *(0,029)$ & $0,213 *(0,023)$ & $0,250 *(0,014)$ & $0,223 *(0,012)$ \\
\hline Idade2 & $0,001 *(0,001)$ & $0,001 *(0,001)$ & $0,001 *(0,001)$ & $0,001 *(0,001)$ \\
\hline Sem instrução & $0,024(0,0245)$ & $0,026(0,017)$ & $0,016(0,0107)$ & $0,0308 *(0,009)$ \\
\hline $1^{\circ}$ Grau completo & $-0,131^{*}(0,079)$ & $-0,134^{*}(0,039)$ & $0,086^{*}(0,051)$ & $-0,047^{*}(0,024)$ \\
\hline $2^{\circ}$ Grau incompleto & $-0,184 *(0,077)$ & $-0,047^{*}(0,037)$ & $-0,113 *(0,065)$ & $-0,054^{*}(0,022)$ \\
\hline $\begin{array}{l}2^{\circ} \text { Grau completo } \\
\text { superior }\end{array}$ & $-0,106(0,108)$ & $-0,189 *(0,076)$ & $-1,545^{*}(0,055)$ & $-0,275^{*}(0,082)$ \\
\hline Chefe & $0,141 *(0,029)$ & $0,067 *(0,020)$ & $0,098 *(0,013)$ & $0,057^{*}(0,011)$ \\
\hline Branca & $0,036 *(0,026)$ & $0,015 *(0,019)$ & $0,024 *(0,011)$ & $0,010 *(0,010)$ \\
\hline Formal & $-0,071 *(0,042)$ & $-0,062 *(0,033)$ & $-0,084 *(0,0272)$ & $-0,165^{*}(0,021)$ \\
\hline Maranhão & 14) & $0,116 *(0,036)$ & $0,013 *(0,019)$ & $0,064 *(0,015)$ \\
\hline Piauí & $0,195 *(0,045)$ & $-0,027 *(0,040)$ & $0,037^{*}(0,019)$ & $-0,064 *(0,021)$ \\
\hline Ceará & $0,056^{*}(0,041)$ & $0,140 *(0,033)$ & $-0,016^{*}(0,019)$ & $0,076 *(0,016)$ \\
\hline Rio Grande do Norte & $0,069 *(0,063)$ & $-0,040 *(0,045)$ & $-0,003 *(0,034)$ & $-0,020 *(0,027)$ \\
\hline Paraíba & $0,162 *(0,048)$ & $-0,030 *(0,040)$ & $0,029 *(0,023)$ & $-0,030^{*}(0,025)$ \\
\hline Alagoas & $-0,106^{*}(0,050)$ & $-0,013^{*}(0,056)$ & $-0,066^{*}(0,036)$ & $0,067^{*}(0,017)$ \\
\hline Sergipe & $0,024 *(0,050)$ & $0,009 *(0,053)$ & $-0,009 *(0,026)$ & $-0,029 *(0,023)$ \\
\hline Bahia & $-0,011 *(0,038)$ & $0,039 *(0,032)$ & $-0,0498 *(0,017)$ & $0,015^{*}(0,013)$ \\
\hline Constante & $4,299 *(0,077)$ & $4,604 *(0,063)$ & $4,464^{*}(0,025)$ & $4,622 *(0,023)$ \\
\hline
\end{tabular}

Fonte: Elaboração própria a partir dos dados da PNAD.

Notas: O valor apresentado é o coeficiente. O desvio-padrão é apresentado entre parênteses. * indica significância no nível de 0,10. 
A análise seguinte refere-se ao setor industrial. Devido ao reduzido número de observações para o setor rural, tendo em vista seu pouco dinamismo nesse espaço regional, muitos coeficientes não apresentaram significância estatística, comprometendo, portanto, a análise espacial. Em relação à zona urbana, os homens apresentaram maior rotatividade no emprego em relação às mulheres. Além disso, a idade novamente está associada a uma menor rotatividade. Foi possível constatar, ainda, que os indivíduos com menor escolaridade apresentam maior rotatividade, ocorrendo o inverso com o aumento do nível escolar. De forma similar à análise feita em relação ao setor agrícola, os chefes-de-família e os brancos apresentam maior permanência, ao passo que os ocupados no segmento formal, maior rotatividade. No espaço rural não é possível ser feita a associação entre todos os níveis de escolaridade e o tempo de permanência na atividade, devido à insignificância dos parâmetros. No entanto, em 2003, os coeficientes das variáveis sem instrução e $2^{\circ}$ grau incompleto indicam que, quanto maior o investimento em capital humano feito pelo trabalhador ocupado no setor rural, maior tende a ser sua rotatividade no emprego - fato não verificado no espaço urbano. Novamente, recorre-se a hipótese da dinâmica do emprego rural, no qual trabalhadores mais qualificados estão em constante busca por ocupações associadas a maiores rendimentos, remunerando melhor o maior investimento em capital humano dado que, de uma forma geral, nas zonas rurais o nível salarial é inferior ao observado nos centros urbanos. 
Tabela 7. Resultados do modelo paramétrico no setor industrial, por ano (1993 e 2003)

\begin{tabular}{|c|c|c|c|c|}
\hline \multirow{2}{*}{ Variável } & \multicolumn{2}{|c|}{ ÁREA URBANA } & \multicolumn{2}{|c|}{ ÁREA RURAL } \\
\hline & 1993 & 2003 & 1993 & 2003 \\
\hline Homem & $-0,073 *(0,038)$ & $-0,116^{*}(0,042)$ & $-0,616(0,142)$ & $-0,367^{*}(0,094)$ \\
\hline Idade & $0,289 *(0,041)$ & $0,349 *(0,050)$ & $-0,098(0,135)$ & $0,194(0,071)$ \\
\hline Idade2 & $0,001 *(0,001)$ & $0,001 *(0,001)$ & $0,001 *(0,002)$ & $0,001 *(0,001)$ \\
\hline Sem instrução & $-0,030 *(0,040)$ & $0,141^{*}(0,063)$ & $-0,205(0,100)$ & $0,076^{*}(0,060)$ \\
\hline $1^{\circ}$ Grau completo & $-0,046^{*}(0,049)$ & $0,087^{*}(0,058)$ & $-0,139(0,289)$ & $-0,035(0,111)$ \\
\hline $2^{\circ} \mathrm{Grau}$ incompleto & $0,137 *(0,036)$ & $0,167^{*}(0,042)$ & $0,366(0,221)$ & $-0,037^{*}(0,073)$ \\
\hline $\begin{array}{l}2^{\circ} \text { Grau completo } \\
\text { superior }\end{array}$ & $0,181 *(0,049)$ & $0,407^{*}(0,074)$ & $0,027(0,613)$ & $-0,462(0,204)$ \\
\hline Chefe & $0,238^{*}(0,035)$ & $0,063 *(0,040)$ & $0,058(0,118)$ & $0,180 *(0,072)$ \\
\hline Branca & $0,066^{*}(0,029)$ & $0,093 *(0,040)$ & $0,041(0,101)$ & $-0,004 *(0,050)$ \\
\hline Formal & $-0,103^{*}(0,032)$ & $-0,027 *(0,037)$ & $0,362(0,116)$ & $-0,266 *(0,074)$ \\
\hline Maranhão & $0,049 *(0,074)$ & $0,235^{*}(0,084)$ & $1,216(0,210)$ & $0,116(0,125)$ \\
\hline Piauí & $0,014 *(0,076)$ & $-0,122(0,109)$ & $1,057(0,240)$ & $0,123(0,118)$ \\
\hline Ceará & $-0,024^{*}(0,040)$ & $0,102 *(0,053)$ & $0,594(0,132)$ & $0,213 *(0,090)$ \\
\hline Rio Grande do Norte & $0,133 *(0,066)$ & $0,097^{*}(0,090)$ & $1,083(0,161)$ & $-0,099(0,106)$ \\
\hline Paraíba & $0,130 *(0,069)$ & $-0,034^{*}(0,089)$ & $1,159(0,267)$ & $0,152(0,113)$ \\
\hline Alagoas & $0,047^{*}(0,072)$ & $-0,019(0,114)$ & $1,326(0,198)$ & $0,233(0,129)$ \\
\hline Sergipe & $-0,001 *(0,064)$ & $0,116^{*}(0,090)$ & $0,958(0,237)$ & $-0,003(0,125)$ \\
\hline Bahia & $0,003 *(0,038)$ & $0,0370 *(0,054)$ & $0,982(0,158)$ & $0,170(0,096)$ \\
\hline Constante & $3,182 *(0,083)$ & $2,241 *(0,076)$ & $2,273(0,197)$ & $4,156(0,175)$ \\
\hline
\end{tabular}

Fonte: Elaboração própria a partir dos dados da PNAD.

Notas: O valor apresentado é o coeficiente. O desvio-padrão é apresentado entre parênteses. * indica significância no nível de 0,10.

Em relação aos resultados para o setor terciário (comércio) percebese que os homens tendem a apresentar maior tempo de permanência em relação às mulheres e que a elevação da idade está associada a uma menor rotatividade no emprego. Mais uma vez, a variável educação apresentou relação direta com o tempo de permanência na ocupação, independente da área estudada. Quanto ao aspecto regional, verificase que os residentes no Ceará, Rio Grande do Norte, Paraíba e Alagoas 
apresentam maior duração do que os residentes em Pernambuco, principalmente na área urbana (1993) e rural (2003).

Tabela 8. Resultados do modelo paramétrico no setor de comércio, por ano (1993 e 2003)

\begin{tabular}{|c|c|c|c|c|}
\hline \multirow{2}{*}{ Variável } & \multicolumn{2}{|c|}{ ÁREA URBANA } & \multicolumn{2}{|c|}{ ÁREA RURAL } \\
\hline & 1993 & 2003 & 1993 & 2003 \\
\hline Homem & $0,938(0,125)$ & $0,835^{*}(0,021)$ & $0,098 *(0,035)$ & $0,780(0,094)$ \\
\hline Idade & $0,720(0,111)$ & $0,693 *(0,021)$ & $0,301 *(0,041)$ & $0,701(0,090)$ \\
\hline Idade2 & $0,999 *(0,001)$ & $0,999 *(0,001)$ & $0,001 *(0,001)$ & $0,999 *(0,001)$ \\
\hline Sem instrução & $1,028(0,130)$ & $0,981 *(0,042)$ & $0,023 *(0,047)$ & $1,113(0,156)$ \\
\hline $1^{\circ}$ Grau completo & $1,549(0,316)$ & $1,035 *(0,040)$ & $-0,086^{*}(0,052)$ & $1,425(0,202)$ \\
\hline $2^{\circ} \mathrm{Grau}$ incompleto & $1,169(0,189)$ & $1,050 *(0,027)$ & $0,013 *(0,036)$ & $1,109(0,1432)$ \\
\hline $\begin{array}{l}2^{\circ} \text { Grau completo } \\
\text { superior }\end{array}$ & $1,512(0,401)$ & $0,980 *(0,046)$ & $0,071(0,059)$ & $2,197(0,577)$ \\
\hline Chefe & $0,851(0,116)$ & $0,876^{*}(0,022)$ & $0,128 *(0,036)$ & $0,943(0,117)$ \\
\hline Branca & $0,952 *(0,093)$ & $0,930 *(0,021)$ & $-0,009 *(0,030)$ & $0,849(0,087)$ \\
\hline Formal & $0,871(0,118)$ & $1,068 *(0,025)$ & $-0,014 *(0,033)$ & $1,289(0,164)$ \\
\hline Maranhão & $1,292(0,213)$ & $1,185^{*}(0,062)$ & $-0,005 *(0,089)$ & $0,917(0,163)$ \\
\hline Piauí & $0,748(0,163)$ & $1,040 *(0,059)$ & $-0,195 *(0,080)$ & $1,030(0,237)$ \\
\hline Ceará & $0,839(0,152)$ & $1,054^{*}(0,035)$ & $0,027^{*}(0,041)$ & $0,787(0,119)$ \\
\hline Rio Grande do Norte & $0,825(0,198)$ & $1,147 *(0,064)$ & $0,150 *(0,073)$ & $1,174(0,238)$ \\
\hline Paraíba & $0,705(0,1613)$ & $1,007 *(0,049)$ & $0,228 *(0,059)$ & $0,981(0,205)$ \\
\hline Alagoas & $0,931(0,198)$ & $1,124 *(0,070)$ & $0,047^{*}(0,068)$ & $0,855(0,191)$ \\
\hline Sergipe & $0,541(0,1407)$ & $0,934 *(0,045)$ & $0,116(0,073)$ & $0,788(0,140)$ \\
\hline Bahia & $1,001(0,167)$ & $1,054 *(0,032)$ & $-0,024 *(0,040)$ & $1,190(0,158)$ \\
\hline Constante & - & - & $2,967(0,070)$ & - \\
\hline
\end{tabular}

Fonte: Elaboração própria a partir dos dados da PNAD.

Notas: O valor apresentado é o coeficiente. O desvio-padrão é apresentado entre parênteses. ${ }^{*}$ indica significância no nível de 0,10 .

Finalmente, ao analisar o ramo de atividade serviços, nota-se que os resultados se mantêm. Os homens (em 2003), com mais idade, chefesde-família, brancos e ocupados no segmento formal apresentam maior duração no emprego. Por outro lado, indivíduos com maior escolaridade apresentam rotatividade mais elevada quando comparado àqueles com primeiro grau incompleto. Com exceção da Bahia, os demais 
estados analisados garantem maior permanência no emprego quando comparados a Pernambuco.

Tabela 9. Resultados do modelo paramétrico no setor de serviços, por ano (1993 e 2003)

\begin{tabular}{l|c|c|c|c}
\hline \multirow{2}{*}{ Variável } & \multicolumn{2}{|c|}{ ÁREA URBANA } & \multicolumn{2}{c}{ ÁREA RURAL } \\
\cline { 2 - 5 } & $\mathbf{1 9 9 3}$ & $\mathbf{2 0 0 3}$ & $\mathbf{1 9 9 3}$ & $\mathbf{2 0 0 3}$ \\
\hline Homem & $-0,044^{*}(0,018)$ & $0,038^{*}(0,016)$ & $-0,224^{*}(0,062)$ & $0,929^{*}(0,063)$ \\
\hline Idade & $0,356^{*}(0,023)$ & $0,415^{*}(0,020)$ & $0,292(0,068)$ & $0,691(0,057)$ \\
\hline Idade2 & $0,001^{*}(0,001)$ & $0,001^{*}(0,001)$ & $0,001^{*}(0,001)$ & $0,999^{*}(0,001)$ \\
\hline Sem instrução & $-0,084^{*}(0,029)$ & $-0,011^{*}(0,033)$ & $-0,143(0,066)$ & $1,122(0,104)$ \\
\hline $1^{\circ}$ Grau completo & $0,015^{*}(0,028)$ & $-0,025^{*}(0,028)$ & $0,320^{*}(0,079)$ & $0,931(0,101)$ \\
\hline $2^{\circ}$ Grau incompleto & $0,095^{*}(0,019)$ & $0,069^{*}(0,018)$ & $0,155^{*}(0,059)$ & $0,889^{*}(0,057)$ \\
\hline $2^{\circ}$ Grau completo & $0,132^{*}(0,021)$ & $0,108^{*}(0,021)$ & $0,251^{*}(0,084)$ & $0,685^{*}(0,071)$ \\
\hline \multicolumn{1}{c}{ superior } & $0,104^{*}(0,019)$ & $0,080^{*}(0,016)$ & $0,084^{*}(0,068)$ & $1,094^{*}(0,073)$ \\
\hline Chefe & $0,040^{*}(0,015)$ & $-0,007^{*}(0,015)$ & $-0,040^{*}(0,050)$ & $0,968(0,062)$ \\
\hline Branca & $0,098^{*}(0,019)$ & $0,313^{*}(0,016)$ & $0,092^{*}(0,059)$ & $0,588^{*}(0,035)$ \\
\hline Formal & $0,089^{*}(0,048)$ & $0,097^{*}(0,038)$ & $0,061^{*}(0,082)$ & $0,864(0,113)$ \\
\hline Maranhão & $0,046^{*}(0,038)$ & $0,078^{*}(0,036)$ & $0,171^{*}(0,097)$ & $0,904(0,112)$ \\
\hline Piauí & $0,065^{*}(0,023)$ & $-0,021^{*}(0,021)$ & $0,061^{*}(0,089)$ & $0,710^{*}(0,078)$ \\
\hline Ceará & $0,154^{*}(0,035)$ & $0,016^{*}(0,034)$ & $0,247(0,101)$ & $0,912(0,105)$ \\
\hline Rio Grande do Norte & $0,081^{*}(0,032)$ & $0,149^{*}(0,029)$ & $0,017(0,104)$ & $0,656^{*}(0,079)$ \\
\hline Paraíba & $0,035^{*}(0,039)$ & $0,022^{*}(0,037)$ & $0,040(0,113)$ & $0,576^{*}(0,070)$ \\
\hline Alagoas & $-0,010^{*}(0,035)$ & $0,053^{*}(0,032)$ & $0,079(0,107)$ & $0,638(0,109)$ \\
\hline Sergipe & $-0,050^{*}(0,020)$ & $-0,054^{*}(0,019)$ & $-0,117^{*}(0,080)$ & $0,876^{*}(0,087)$ \\
\hline Bahia & $3,078^{*}(0,050)$ & $2,747^{*}(0,041)$ & $3,221(0,134)$ & - \\
\hline Constante & & &
\end{tabular}

Fonte: Elaboração própria a partir dos dados da PNAD.

Notas: O valor apresentado é o coeficiente. O desvio-padrão é apresentado entre parênteses. * indica significância no nível de 0,10.

\section{Considerações finais}

Os resultados encontrados mostraram que alguns dos determinantes do emprego tendem a se manter ao longo dos anos pesquisados, independente do setor analisado. Atributos como o sexo (no caso, homem), chefes-de-família, raça (brancos), idade (mais elevada) e escolaridade 
(menor) possuem uma forte relação com a duração no emprego. Assim, os resultados do modelo paramétrico pouco se alteraram com o decorrer do tempo e vão ao encontro dos sugeridos pela literatura. Duas observações importantes foram constatadas: a) quanto maior a idade, maior tende a ser a permanência no emprego; b) quanto maior o nível de escolaridade, maior a rotatividade. A explicação pode estar associada ao baixo nível de qualificação (capital humano) que não permite ao indivíduo alcançar outras atividades de maior remuneração.

No entanto, em decorrência da realidade econômica dos estados da região Nordeste e do período de análise (1993 e 2003), algumas variáveis explicativas podem interferir de forma diferenciada. Destaca-se, a maior rotatividade do emprego apresentada pelos trabalhadores ocupados no segmento formal da economia (setores primário e secundário), que pode ser reflexo do contexto econômico de competitividade crescente que, aliado a uma rígida legislação trabalhista, pode estar contribuindo não apenas para o aumento da rotatividade da mão-de-obra, mas também para o aumento relativo dos ocupados sem carteira assinada. Provavelmente, este fato se deve às elevadas taxas de desemprego, que acabam forçando a alta rotatividade do emprego, principalmente nos setores citados.

Em relação às diferenças regionais, verificou-se que os trabalhadores de Pernambuco e da Bahia apresentaram maiores índices de transição no emprego - estes são, justamente, os estados detentores das maiores taxas de desemprego da região analisada. Por fim, o diagnóstico acerca da análise por área rural e urbana mostrou que os determinantes da duração do emprego são praticamente os mesmos, independentemente do espaço geográfico em que está inserido o trabalhador; o que se modifica é a sua intensidade. 


\section{Referências bibliográficas}

BARROS, Ricardo Paes de, CORSEUIL, Carlos Henrique e FOGUEL, Miguel. Os incentives adversos e a focalização dos programas de proteção ao trabalhador no Brasil, Planejamento e Políticas Públicas. 2002.

BIVAR, Wasmália Socorro Barata. Aspectos da estrutura do desemprego no Brasil: composição por sexo e duração. BNDES, Rio de Janeiro. 1993.

CHAHAD, José Paulo Zeetano; ORELLANO, V, e Picchetti, Paulo. A bivariate probit analisys of Job Turnover in Brazil, Anais do Encontro Brasileiro de Econometria. 2001.

CHUANG, Hwei-Lin. Estimating the determinants of the unemployment duration for college graduates in Taiwan. Applied Economics Letters, Vol 6, nº 10. 1999.

COLOSIMO, Enrico Antônio. Análise de sobrevivência aplicada. Apostila do curso ministrado na Reunião Anual da Região Brasileira da Sociedade Internacional de Biometria e no Simpósio de Estatística Aplicada à experimentação. Piracicaba. São Paulo. 2001.

CORSEUIL, Carlos Henrique; RIBEIRO, E, P. e SANTOS, D. Job and Worker Flows in Brazil. Mimeo, 2003.

FARBER, Henry S. Mobility and stability: The dynamics of job change in labor markets. In: Ashenfelter \& D, Card (ed.) Handbook of Labor Economics. Edition 1, vol. 3, chapter 37, pages 2439-2483. Elsevier. 1999.

GONZAGA, Gustavo. Labor Turnover and Labor Legislation in Brazil. Departamento de Economia: PUC-Rio. Texto para discussão, n 475. 2003.

GRAZIANO DA SILVA, José. O novo rural brasileiro. Campinas, Unicamp/IE, Coleção Pesquisas, n.1. 1999.

HALIMA, Mohamed Ali Bem. The determinants for labour contract length: A French micro-econometric study. Mars 2005. Disponível em 
< http://www.gate.cnrs.fr/documentation/workingpapers/2005/0503. pdf $>$. Acesso em 17 de abril de 2006.

MENEZES FILHO, Naércio, e FERNANDES, Reynaldo. The Costs of Displacement in Brazil. Mimeo. 2003.

MENEZES, Naércio Aquino; PICHETTI, Paulo e FERNANDES, Reynaldo. Uma Análise da Duração das Relações de Emprego em São Paulo - 1988 A 1999, Ministério do Trabalho e Emprego: Estudos e análise com vistas à definição de políticas, programas e projetos relativos ao mercado de trabalho brasileiro, São Paulo. 2002.

MOREIRA, Ivan Targino, Êxodo rural na Paraíba: análise do período 1991/96. In: Taís de Freitas (Org.). Dinâmica populacional das regiões Norte e Nordeste: questões atuais e mergenciais. Recife: Massangana, vol. 1, p. 83-105. 2000.

RAMOS, Carlos Alberto e CARNEIRO, Francisco Galrão. Os determinantes da rotatividade do trabalho no Brasil: instituições $\mathrm{x}$ ciclos econômicos. Nova Economia, Belo Horizonte. 2002. 